\title{
Asthma, Foot Drop, and Palpable Purpura in a Young Woman
}

\author{
Gabriela Kuftinec, MD, MPH, Maha Sami, MD, and Paul Aronowitz, MD \\ Department of Internal Medicine, School of Medicine, University of California, Davis, Sacramento, CA, USA.
}

KEY WORDS: Churg-Strauss syndrome; eosinophilic granulomatosis with polyangiitis (EGPA); asthma; tissue eosinophilia; medium-vessel vasculitis.

J Gen Intern Med 32(12): 1405

DOI: $10.1007 / \mathrm{s} 11606-017-4096-9$

(๑) Society of General Internal Medicine 2017
A 28-year-old woman with poorly controlled asthma presented with 1 week of a painful non-pruritic rash, 4 days of fevers and abdominal pain, and 1 day of a left foot drop. Examination revealed palpable purpura on the abdomen (Fig. 1), back, and lower extremities (Fig. 2). Respiratory wheezes, diffuse abdominal tenderness, and a left foot drop with $0 / 5$ strength were present. Blood count with differential was remarkable for $56 \%$ eosinophils. A diagnosis of eosinophilic granulomatosis with polyangiitis (EGPA) was made.

EGPA, formerly Churg-Strauss syndrome, is a rare, smallto medium-vessel vasculitis characterized by eosinophilic infiltration of organs with necrotizing granulomas. ${ }^{1}$ There are typically three phases: difficult-to-control asthma, followed by blood and tissue eosinophilia, and ultimately systemic necrotizing vasculitis. The vasculitic phase includes mononeuritis multiplex in $75 \%$ of cases. ${ }^{2}$ Dermatologic manifestations include tender subcutaneous nodules, maculopapular rash, and non-thrombocytopenic petechiae and palpable purpura. ${ }^{1}$

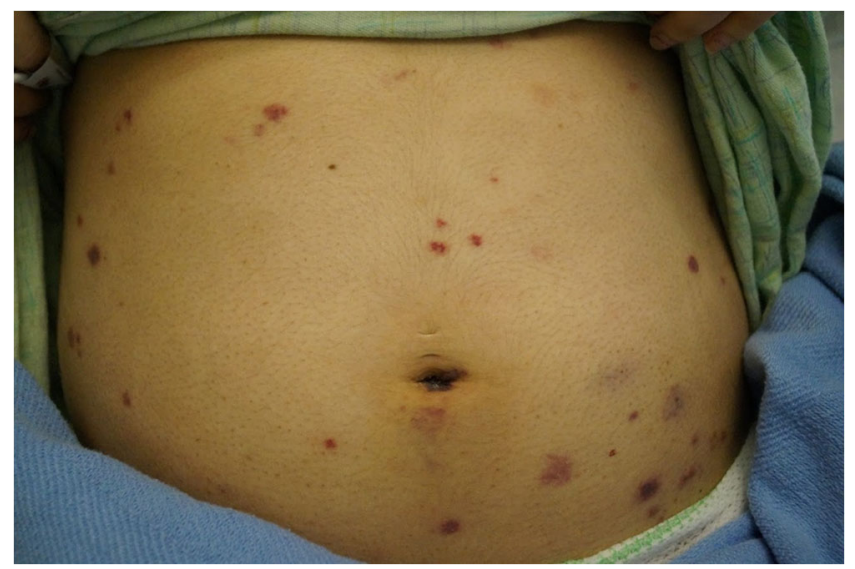

Figure 1 Palpable purpura on abdomen.

Received March 7, 2017

Revised May 1, 2017

Accepted May 30, 2017

Published online June 15, 2017

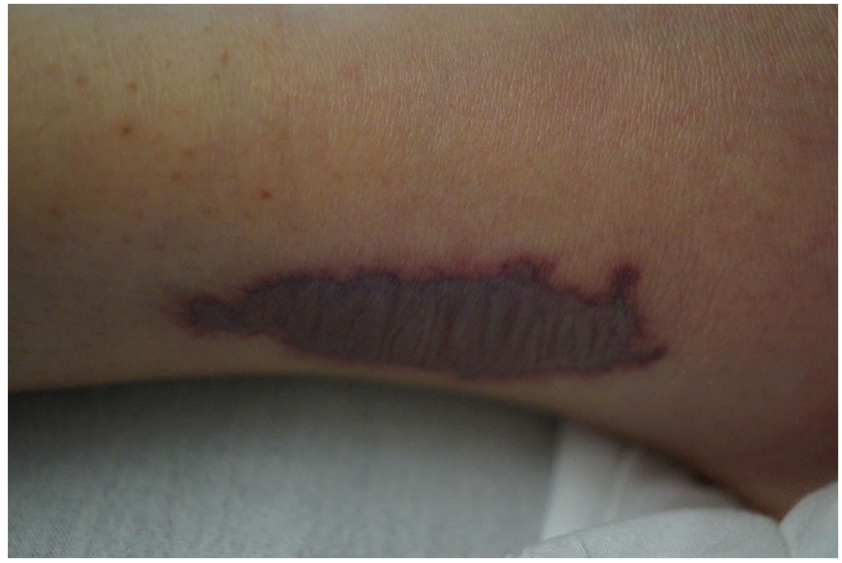

Figure 2 Palpable purpura on right lateral aspect of ankle.

EGPA is highly steroid-responsive, with long-term survival of $90 \%$ over 20 years. ${ }^{3}$ After treatment with high-dose steroids was started, the patient's symptoms improved markedly. She went on to receive azathioprine for maintenance therapy and physical therapy for her foot drop.

Corresponding Author: Paul Aronowitz, MD; Department of Internal Medicine, School of MedicineUniversity of California, Davis, $4150 \mathrm{~V}$ Street, Suite 3100, Sacramento, CA 95817, USA (e-mail: Paronowitz@ucdavis.edu).

\section{Compliance with Ethical Standards:}

Conflict of Interest: The authors declare that they do not have a conflict of interest.

\section{REFERENCES}

1. Noth I, Strek M, Leff A. Churg-Strauss syndrome. Lancet. 2003;361:587-594.

2. Sehgal M, Swanson J, Deremee R, Colby T. Neurologic manifestations of Churg-Strauss syndrome. Mayo Clin Proc. 1995;70:337-41.

3. Solans R, Bosch JA, Pérez-Bocanegra C, et al. Churg-Strauss syndrome: outcome and long-term follow-up of 32 patients. Rheumatol. 2001;40:763-71. 